\title{
Theoretical Study of Structural and Electronic Properties of H-Silsesquioxanes
}

\author{
Kai-Hua Xiang, ${ }^{\dagger}$ Ravindra Pandey, ${ }^{*}, \dagger$ Udo C. Pernisz, ${ }^{\ddagger}$ and Clive Freeman ${ }^{\S}$ \\ Department of Physics, Michigan Technological University, Houghton, Michigan 49931, \\ Dow Corning Corporation, Midland, Michigan 48686, and Molecular Simulations Inc., \\ San Diego, California 92121
}

Received: April 14, 1998; In Final Form: August 19, 1998

\begin{abstract}
The results of first principles calculations on $\mathrm{H}$-silsesquioxanes (i.e., $\left(\mathrm{HSiO}_{3 / 2}\right)_{n}$ with $n=4,6,8,10,12,14$, and 16) are reported here. Double numeric basis sets and local and nonlocal density approximations to density functional theory are employed for calculations. It is shown that use of the nonlocal density approximation is required for the reliable prediction of the most stable isomer for silsesquioxanes. Furthermore, a progression of the preferred building unit with the increase in size of the $\mathrm{T}$ cage is revealed. The smaller $\mathrm{T}$ cages prefer four- and five-member rings while the larger cages are found to prefer four- and six-member rings. Analysis of the energy of the hydrolysis reaction, binding energy, and fragmentation paths finds the relative stability of the silsesquioxane cages containing four-, five-, and six-member rings in agreement with experimental observations. For the $\left(\mathrm{HSiO}_{3 / 2}\right)_{16}$ cage, the calculated results predict the stability of the $D_{2 d^{-}} 6^{4} 5^{0} 4^{6}$ configuration over the $D_{4 d^{-}}-6^{0} 5^{8} 4^{2}$ configuration in contradiction to suggestions based on ${ }^{29} \mathrm{Si}$ NMR measurements. We find a consistent picture for the highest occupied molecular orbitals (HOMOs) of all silsesquioxanes considered showing them to be composed of (lone-pair) oxygen p-type atomic orbitals. On the other hand, the lowest unoccupied molecular orbitals (LUMOs) show size dependence in their composition which appears to cause the presence of a state in the HOMO-LUMO gap for higher silsesquioxane cages. Density of states plots and analysis of molecular orbitals reveal this state to be due to the terminal hydrogens bonded to silicon atoms.
\end{abstract}

\section{Introduction}

H-silsesquioxanes (HSQ) constitute an important class of resinous inorganic polymers. ${ }^{1-4}$ Their building block is the trifunctional monomer $\left(\mathrm{HSiO}_{3 / 2}\right)$, designated as the $\mathrm{T}$ unit. The structure of the polymer is based on siloxane-containing cages that are formed from the building block unit. For example, the $\mathrm{T}_{8}$ structure forms a cage consisting of 8 silicon atoms that are connected by oxygen atoms to each other, whereas the $\mathrm{T}_{16}$ structure has a cage comprising 16 silicon atoms (Figures 1 and 2 ). The cross-linking of various siloxane-containing cages leads to a wide range in the distribution of molecular masses up to $200 \mathrm{kDa}$ for the polymer. The cagelike structure of smaller T cages can also be considered as a building block for zeolite and silicate frameworks. For example, ring-opening vibrations of $\mathrm{T}$ cages were considered recently as a model system for the pore-opening vibrations of zeolites. ${ }^{5-7}$

The HSQ polymer is soluble in organic solvents, and the solution can be spin-cast to give thin films of HSQ that can be converted to low-density silica by heating in oxygen. As it is heated, the material undergoes a phase transition at approximately $200{ }^{\circ} \mathrm{C}$ during which it softens and flows. The film will not melt again after it has been converted. Therefore, gap fill and planarization on electronic circuits can be achieved by low-temperature processing of the polymer in a suitable atmosphere which enables the application of these films in the semiconductor industry for the manufacture of integrated circuits. $^{8}$ It was also observed that thin films of HSQ sandwiched between metal electrodes can exhibit bistability of the

\footnotetext{
† Michigan Technological University.

$\doteqdot$ Dow Corning Corporation.

$\S$ Molecular Simulations Inc.
}

electric current-voltage characteristics in an inert atmosphere. ${ }^{9}$ Under these circumstances, the current through the device is higher by several orders of magnitude than the insulating state, a reversible phenomenon that requires the presence of electronic states which facilitates the charge carrier transport in the material.

Although the synthesis of silsesquioxanes $\left(\mathrm{HSiO}_{3 / 2}\right)_{n}$ with $n$ $=8,10,12,14$, and 16 has been reported, ${ }^{2-14}$ there is a lack of information about electronic properties of silsesquioxanes, and the task of measuring and understanding these properties has become increasingly important for its technical application. In this paper, we perform such a task with two objectives: (i) determination of the ground-state configurations of the $\mathrm{T}_{n}$ cages with $n=4,6,8,10,12,14$, and 16 and (ii) prediction of the variation in electronic properties with the increase in cage size. We will consider various configurations of a given $\mathrm{T}$ cage and will perform total energy calculations to optimize its structural parameters, such as bond lengths and bond angles. For the optimized configurations, a trend in electronic properties will then be obtained by the analysis of molecular orbital energies and coefficients, electronic density maps, and density of states plots. In section 2, details of the computational techniques employed in this study are given. The results are presented and discussed in relation to experiments and previous calculations on the basis of the Hartree-Fock approximation in section 3. We give a summary and conclusions of this study in section 4.

\section{Methods}

All electron calculations on the $\mathrm{T}_{n}$ cages were performed in the framework of density functional theory using the program 


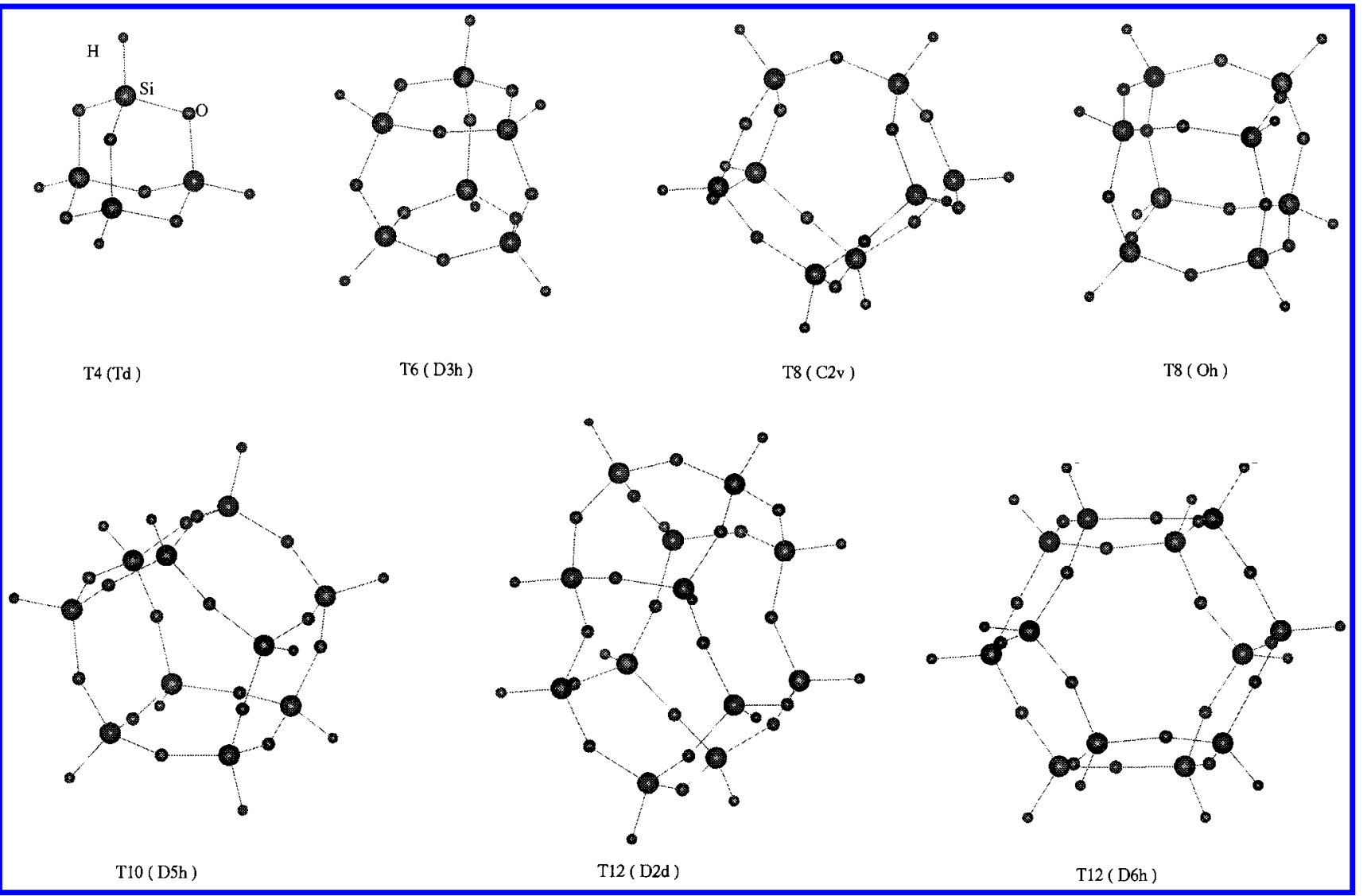

Figure 1. Optimized configurations of $\mathrm{T}_{4}, \mathrm{~T}_{6}, \mathrm{~T}_{8}, \mathrm{~T}_{10}$, and $\mathrm{T}_{12}$ obtained in the nonlocal density approximation.

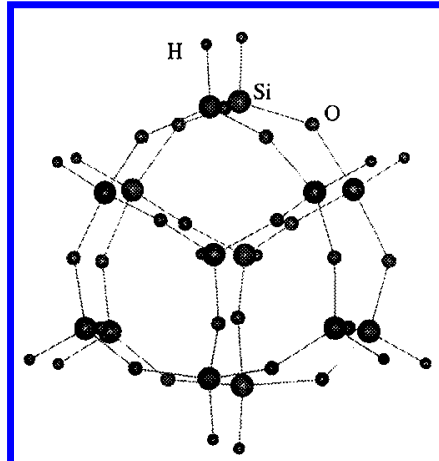

T14 (D3h)

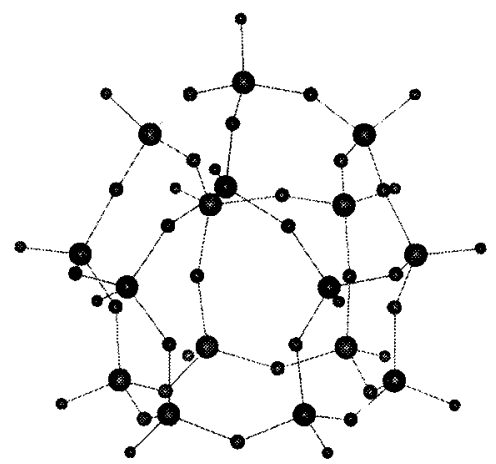

$\mathrm{T} 16(\mathrm{C} 3 \mathrm{v})$

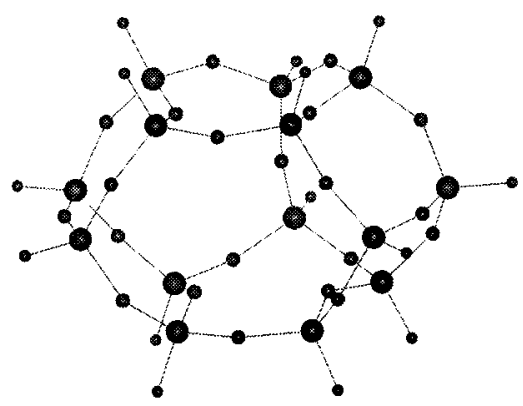

$\mathrm{T} 14(\mathrm{C} 2 \mathrm{v})$

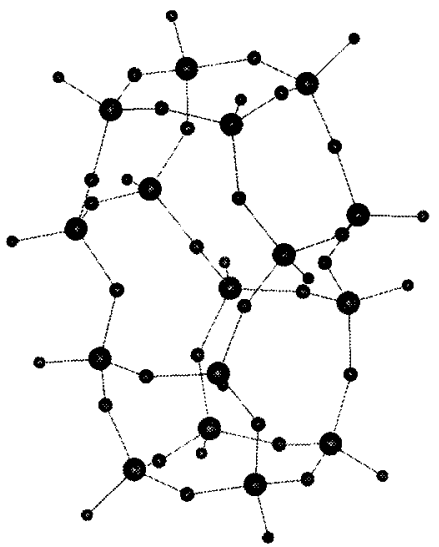

$\mathrm{T} 16(\mathrm{D} 2 \mathrm{~d})$

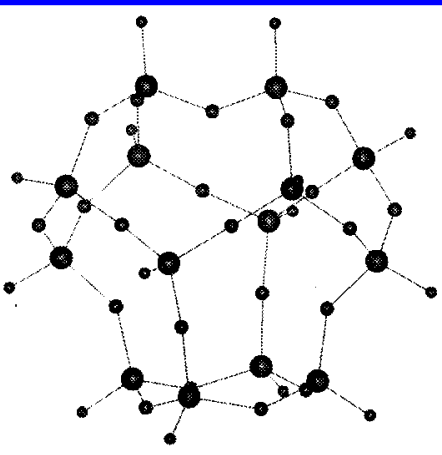

T14 (D3h)

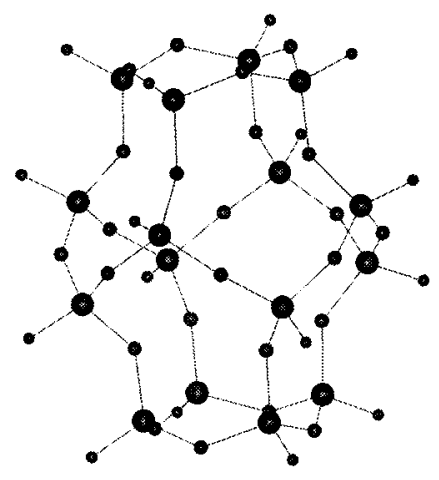

Figure 2. Optimized configurations of $\mathrm{T}_{14}$ and $\mathrm{T}_{16}$ obtained in the nonlocal density approximation.

package DMol. ${ }^{15}$ We considered both local and nonlocal spin density approximations for the calculations. The Vosko-Wilk-
Nusair local exchange and correlation functional ${ }^{16}$ was used for the local density approximation (LDA) whereas a combination 
TABLE 1: Total Energies for Various Configurations of Silsesquioxane Cages

\begin{tabular}{|c|c|c|c|c|c|c|c|c|c|}
\hline & \multirow[b]{2}{*}{ building unit } & \multirow[b]{2}{*}{ sym } & \multirow[b]{2}{*}{ state } & \multicolumn{3}{|c|}{ total energy (hartrees) } & \multicolumn{3}{|c|}{ relative energy $/ \mathrm{Si}$ atom $(\mathrm{kcal} / \mathrm{mol})$} \\
\hline & & & & LDA & NLDA & $\mathrm{HF}^{22}$ & LDA & NLDA & $\mathrm{HF}^{23}$ \\
\hline $\mathrm{T}_{4}\left(\mathrm{H}_{4} \mathrm{Si}_{4} \mathrm{O}_{6}\right)$ & $5^{0} 4^{0} 3^{4}$ & $T_{d}$ & $\mathrm{~T}_{1}$ & -1604.8263 & -1616.1841 & -1607.762 & 0 & 0 & 0 \\
\hline $\mathrm{T}_{6}\left(\mathrm{H}_{6} \mathrm{Si}_{6} \mathrm{O}_{9}\right)$ & $5^{0} 4^{3} 3^{2}$ & $D_{3 h}$ & $\mathrm{E}^{\prime}$ & -2407.2967 & -2424.3336 & -2411.716 & -5.9 & -6.0 & -7.6 \\
\hline \multirow[t]{2}{*}{$\mathrm{T}_{8}\left(\mathrm{H}_{8} \mathrm{Si}_{8} \mathrm{O}_{12}\right)$} & $6^{0} 5^{0} 4^{6}$ & $O_{h}$ & $\mathrm{~A}_{2 \mathrm{~g}}$ & -3209.7425 & -3232.4608 & -3215.652 & -7.0 & -7.3 & -10.0 \\
\hline & $5^{2} 4^{2} 3^{2}$ & $C_{2 v}$ & $\mathrm{~B}_{1}$ & -3209.7383 & -3232.4534 & -3215.639 & -6.7 & -6.7 & -8.9 \\
\hline $\mathrm{T}_{10}\left(\mathrm{H}_{10} \mathrm{Si}_{10} \mathrm{O}_{15}\right)$ & $6^{0} 5^{2} 4^{5}$ & $D_{5 h}$ & $\mathrm{E}_{2}^{\prime}$ & -4012.1756 & -4040.5737 & -4019.571 & -6.9 & -7.1 & -10.3 \\
\hline \multirow[t]{2}{*}{$\mathrm{T}_{12}\left(\mathrm{H}_{12} \mathrm{Si}_{12} \mathrm{O}_{18}\right)$} & $6^{0} 5^{4} 4^{4}$ & $D_{2 d}$ & $\mathrm{E}$ & -4814.6188 & -4848.6856 & -4823.489 & -7.3 & -7.0 & -10.5 \\
\hline & $6^{2} 5^{0} 4^{6}$ & $D_{6 h}$ & $\mathrm{~B}_{2 \mathrm{u}}$ & -4814.6085 & -4848.6846 & -4823.485 & -6.8 & -6.9 & -10.3 \\
\hline \multirow{3}{*}{$\mathrm{T}_{14}\left(\mathrm{H}_{14} \mathrm{Si}_{14} \mathrm{O}_{21}\right)$} & $6^{0} 5^{6} 4^{3}$ & $D_{3 h}$ & $\mathrm{~A}_{1}^{\prime \prime}$ & -5617.0518 & -5656.8071 & & -7.2 & -7.3 & \\
\hline & $6^{1} 5^{4} 4^{4}$ & $C_{2 v}$ & $\mathrm{~A}_{2}$ & -5617.0581 & -5656.8048 & & -7.4 & -7.2 & \\
\hline & $6^{3} 5^{0} 4^{6}$ & $D_{3 h}$ & $\mathrm{~A}_{1}^{\prime \prime}$ & -5616.6062 & -5656.2325 & & +12.8 & +18.4 & \\
\hline \multirow[t]{3}{*}{$\mathrm{T}_{16}\left(\mathrm{H}_{16} \mathrm{Si}_{16} \mathrm{O}_{24}\right)$} & $6^{0} 5^{8} 4^{2}$ & $D_{4 d}$ & $\mathrm{~A}_{2}$ & -6419.4636 & -6464.9061 & & -6.2 & -6.6 & \\
\hline & $6^{1} 5^{6} 4^{3}$ & $C_{3 v}$ & E & -6419.4868 & -6464.8917 & & -7.1 & -6.1 & \\
\hline & $6^{4} 5^{0} 4^{6}$ & $D_{2 d}$ & $\mathrm{~B}_{2}$ & -6419.4834 & -6464.9273 & & -7.0 & -7.5 & \\
\hline
\end{tabular}

TABLE 2: Selected Bond Lengths and Bond Angles of Silsesquioxanes ${ }^{a}$

\begin{tabular}{|c|c|c|c|c|c|c|c|c|}
\hline & \multirow[b]{2}{*}{ building unit } & \multirow[b]{2}{*}{$\mathrm{NR} / \mathrm{N}^{\prime} \mathrm{R}$} & \multicolumn{2}{|c|}{$R_{\mathrm{Si}-\mathrm{O}}(\mathrm{pm})$} & \multicolumn{2}{|c|}{$A_{\mathrm{SiOSi}}(\mathrm{deg})$} & \multicolumn{2}{|c|}{$A_{\mathrm{OSiO}}(\mathrm{deg})$} \\
\hline & & & LDA & NLDA & LDA & NLDA & LDA & NLDA \\
\hline $\mathrm{T}_{4}$ & $5^{0} 4^{0} 3^{4}\left(T_{d}\right)$ & $3 R / 3 R$ & 167 & 171 & 114.8 & 114.1 & 106.7 & 107.1 \\
\hline \multirow[t]{2}{*}{$\mathrm{T}_{6}$} & $5^{0} 4^{3} 3^{2}\left(D_{3 h}\right)$ & $3 R / 4 R$ & 165 & 169 & 130.0 & 129.1 & & \\
\hline & & $4 \mathrm{R} / 4 \mathrm{R}$ & 165 & 168 & 130.9 & 129.8 & 110.2 & 110.6 \\
\hline \multirow[t]{6}{*}{$\mathrm{T}_{8}$} & $6^{0} 5^{0} 4^{6}\left(O_{h}\right)$ & $4 \mathrm{R} / 4 \mathrm{R}$ & 164 & 168 & 146.5 & 144.6 & 110.4 & 111.3 \\
\hline & $5^{2} 4^{2} 3^{2}\left(C_{2 v}\right)$ & $3 R / 4 R$ & 165 & 169 & 130.2 & 126.4 & & \\
\hline & & $3 \mathrm{R} / 5 \mathrm{R}$ & 165 & 169 & 130.4 & 128.9 & & \\
\hline & & $4 \mathrm{R} / 4 \mathrm{R}$ & 163 & 168 & 179.1 & 146.2 & 109.8 & 110.7 \\
\hline & & $4 \mathrm{R} / 5 \mathrm{R}$ & 164 & 168 & 136.0 & 147.2 & & \\
\hline & & $5 \mathrm{R} / 5 \mathrm{R}$ & 163 & 167 & 142.0 & 139.0 & 110.4 & 110.6 \\
\hline \multirow[t]{2}{*}{$\mathrm{T}_{10}$} & $6^{0} 5^{2} 4^{5}\left(D_{5 h}\right)$ & $4 \mathrm{R} / 4 \mathrm{R}$ & 164 & 167 & 174.6 & 153.3 & 110.4 & 111.7 \\
\hline & & $4 \mathrm{R} / 5 \mathrm{R}$ & 164 & 167 & 140.5 & 149.0 & & \\
\hline \multirow[t]{5}{*}{$\mathrm{T}_{12}$} & $6^{0} 5^{4} 4^{4}\left(D_{2 d}\right)$ & $4 \mathrm{R} / 4 \mathrm{R}$ & 164 & 168 & 150.4 & 147.5 & 110.6 & 111.4 \\
\hline & & $4 \mathrm{R} / 5 \mathrm{R}$ & 164 & 168 & $140.2,144.8$ & $136.7,145.0$ & & \\
\hline & & $5 \mathrm{R} / 5 \mathrm{R}$ & 164 & 168 & 143.6 & 143.8 & 108.8 & 109.9 \\
\hline & $6^{2} 5^{0} 4^{6}\left(D_{6 h}\right)$ & $4 \mathrm{R} / 4 \mathrm{R}$ & 163 & 167 & 164.1 & 162.8 & 111.5 & 112.7 \\
\hline & & $4 \mathrm{R} / 6 \mathrm{R}$ & 163 & 167 & 145.0 & 143.3 & & \\
\hline \multirow[t]{10}{*}{$\mathrm{T}_{14}$} & $6^{0} 5^{6} 4^{3}\left(D_{3 h}\right)$ & $4 \mathrm{R} / 5 \mathrm{R}$ & 163 & 167 & 142.8 & 140.7 & & \\
\hline & & $5 \mathrm{R} / 5 \mathrm{R}$ & 163 & 166 & $136.3,174.6$ & $141.4,168.7$ & 109.5 & 109.0 \\
\hline & $6^{1} 5^{4} 4^{4}\left(C_{2 v}\right)$ & $4 \mathrm{R} / 4 \mathrm{R}$ & 164 & 168 & 158.2 & 158.6 & 110.9 & 111.7 \\
\hline & & $4 \mathrm{R} / 5 \mathrm{R}$ & 164 & 168 & $141.4,146.1$ & $141.3,141.8$ & & \\
\hline & & $4 \mathrm{R} / 6 \mathrm{R}$ & 164 & 168 & 143.9 & 140.1 & & \\
\hline & & $5 \mathrm{R} / 5 \mathrm{R}$ & 164 & 167 & $130.2,140.0$ & $139.8,141.1$ & 109.3 & 109.7 \\
\hline & & $5 \mathrm{R} / 6 \mathrm{R}$ & 163 & 168 & 140.0 & 139.6 & & \\
\hline & $6^{3} 5^{0} 4^{6}\left(D_{3 h}\right)$ & $4 \mathrm{R} / 4 \mathrm{R}$ & 161 & 163 & 119.9 & 122.5 & & \\
\hline & & 4R/6R & 170 & 176 & 124.0 & 126.2 & & \\
\hline & & 6R/6R & 170 & 175 & 168.8 & 174.9 & & \\
\hline \multirow{9}{*}{$\mathrm{T}_{16}$} & $6^{0} 5^{8} 4^{2}\left(D_{4 d}\right)$ & $4 \mathrm{R} / 5 \mathrm{R}$ & 164 & 168 & 154.9 & 134.2 & & \\
\hline & & $5 \mathrm{R} / 5 \mathrm{R}$ & 163 & 168 & $174.3,175.7$ & $137.9,150.5$ & 110.2 & 110.0 \\
\hline & $6^{1} 5^{6} 4^{3}\left(C_{3 v}\right)$ & $4 \mathrm{R} / 5 \mathrm{R}$ & 164 & 167 & $135.2,146.1$ & $131.8,145.0$ & & \\
\hline & & $4 \mathrm{R} / 6 \mathrm{R}$ & 164 & 167 & 146.7 & 144.7 & & \\
\hline & & $5 \mathrm{R} / 5 \mathrm{R}$ & 163 & 167 & $156.7,160.1$ & $154.4,155.3$ & 109.2 & 109.8 \\
\hline & & $5 \mathrm{R} / 6 \mathrm{R}$ & 164 & 168 & 138.1 & 134.5 & & \\
\hline & $6^{4} 5^{0} 4^{6}\left(D_{2 d}\right)$ & $4 \mathrm{R} / 4 \mathrm{R}$ & 164 & 168 & 149.3 & 147.8 & 112.3 & 112.1 \\
\hline & & 4R/6R & 164 & 167 & $147.7,151.7,154.9$ & $140.1,144.8,146.4$ & & \\
\hline & & 6R/6R & 162 & 167 & 157.2 & 133.5 & 108.3 & 108.7 \\
\hline
\end{tabular}

${ }^{a}$ The $N \mathrm{R} / N^{\prime} \mathrm{R}$ refers to the edge shared by $N$-member and $N^{\prime}$-member $(\mathrm{Si}-\mathrm{O}-)$ rings. The bond length $R_{\mathrm{Si}-\mathrm{H}}$ is about $147 \mathrm{pm}$ in both $\mathrm{LDA}$ and NLDA calculations.

of the gradient-corrected exchange functional of Becke ${ }^{17}$ with the Vosko-Wilk-Nusair correlation functional was used for the nonlocal density approximation (NLDA). The double numeric basis sets, ${ }^{18}$ supplemented by diffuse and polarization functions, were employed for $\mathrm{H}, \mathrm{Si}$, and $\mathrm{O}$ atoms. The accuracy of these basis sets has been analyzed in detail by Delley, ${ }^{19}$ and such basis sets were recently used successfully to study structural and electronic properties of oxide clusters. ${ }^{20,21}$ Since calculations proposed in this work are computationally intensive (e.g., the largest cluster considered here consists of 56 atoms with 432 electrons), we used the frozen-core approximation to reduce the computational cost. In this approximation, the $1 \mathrm{~s}^{2}$ core orbital is frozen for oxygen and the $1 \mathrm{~s}^{2}$ and $2 \mathrm{~s}^{2}$ core orbitals are frozen for silicon during total energy calculations. We note that our earlier work has found negligible effects of freezing the core orbitals on the bond length, dissociation energy, and vibrational frequency in oxide clusters. ${ }^{21}$ In the present calculations, the density tolerance was set to $10^{-6}$ au. The geometric parameters were fully optimized under the given symmetry group with a convergence criterion of both energy tolerance and maximum gradient component to be less than $10^{-5}$ hartree and $10^{-3} \mathrm{au}$, respectively. We have not performed frequency calculations on these clusters but note that similar parameters have proven successful in the study of a range of structural properties (see for example ref 21) for complex systems. The reliability of the numerical basis set can also be checked by 
comparison of the calculated structural parameters for the $T_{8}$ cage with experiment ${ }^{12}$ and previous electronic structure calculations. ${ }^{22-24}$ The experimental values obtained from X-ray diffraction measurements for $R_{\mathrm{Si}-\mathrm{O}}, A_{\mathrm{OSiO}}$, and $A_{\mathrm{SiOSi}}$ are 161.9 pm, $109.6^{\circ}$, and $147.5^{\circ}$ respectively.

Calculations ${ }^{22}$ based on the local density approximation using pseudopotentials report $R_{\mathrm{Si}-\mathrm{O}}=162 \mathrm{pm}$ and $A_{\mathrm{SiOSi}}=148.6^{\circ}$ while our LDA calculations using the numerical basis set find $R_{\mathrm{Si}-\mathrm{O}}=164 \mathrm{pm}, A_{\mathrm{OSiO}}=110.4^{\circ}$, and $A_{\mathrm{SiOSi}}=146.5^{\circ}$. On the other hand, the Hartree-Fock calculations ${ }^{23}$ using the 6-31G(d) basis set yield $R_{\mathrm{Si}-\mathrm{O}}=163 \mathrm{pm}, A_{\mathrm{OSiO}}=109^{\circ}$, and $A_{\mathrm{SiOSi}}=$ $149^{\circ}$. Using a double- $\zeta$ plus polarization basis set for $\mathrm{H}$ and $\mathrm{Si}$ and a triple- $\zeta$ plus polarization basis set for $\mathrm{O}$, Hill and Sauer ${ }^{24}$ report $R_{\mathrm{Si}-\mathrm{O}}=162.6 \mathrm{pm}$ and $A_{\mathrm{SiOSi}}=150^{\circ}$. On the basis of this comparison, we therefore find that the double numerical basis set employed here appears to be very well suited for electronic structure calculations of H-silsesquioxanes.

It has been suggested that the molecular connectivity of various $\mathrm{T}$ cages can be described by 3 -valent 3 -connected convex polyhedra in which the vertexes represent the $\mathrm{Si}-\mathrm{H}$ group and the edges represent the $\mathrm{Si}-\mathrm{O}-\mathrm{Si}$ linkage. ${ }^{1-4}$ Following Agaskar and Klemperer, ${ }^{3}$ we use the notation of $N^{n}$ to represent $n \mathrm{~N}$-member rings. For example, the $\mathrm{T}_{14}$ cage may have isomeric configurations given by $6^{0} 5^{6} 4^{3}$ (six five-member and three four-member rings), $6^{1} 5^{4} 4^{4}$ (one six-member, four fivemember, and four four-member rings), $6^{2} 5^{2} 4^{6}$ (two six-member, two five-member, and six four-member rings), and $6^{3} 5^{0} 4^{6}$ (three six-member and six four-member rings). For calculations, we do not consider all of the possible isomers of a $\mathrm{T}$ cage but restrict ourselves to those isomers identified by $\mathrm{X}$-ray diffraction and NMR measurements. ${ }^{10-14}$ These isomers whose symmetry groups are given in parentheses (Schönflies notations) are $\mathrm{T}_{4}$ $\left(T_{d}\right)-5^{0} 4^{0} 3^{3}, \mathrm{~T}_{6}\left(D_{3 h}\right)-5^{0} 4^{3} 3^{2}, \mathrm{~T}_{8}\left(O_{h}\right)-5^{0} 4^{6}$ and $\left(C_{2 v}\right)-5^{2} 4^{2} 3^{2}, \mathrm{~T}_{10}$ $\left(D_{5 h}\right)-6^{0} 5^{2} 4^{5}, \mathrm{~T}_{12}\left(D_{2 d}\right)-6^{0} 5^{4} 4^{4}$ and $\left(D_{6 h}\right)-6^{2} 5^{0} 4,{ }^{6} \mathrm{~T}_{14}\left(D_{3 h}\right)-6^{0} 5^{6} 4^{3}$, $\left(D_{3 h}\right)-6^{3} 5^{0} 4^{6}$, and $\left(C_{2 v}\right)-6^{1} 5^{4} 4^{4}$, and $\mathrm{T}_{16}\left(D_{4 d}\right)-6^{0} 5^{8} 4^{2},\left(D_{2 d}\right)$ $6^{4} 5^{0} 4^{6}$, and $\left(C_{3 v}\right)-6^{1} 5^{6} 4^{3}$. This choice of isomers allows us to see the effect of different faces and edges of a given $\mathrm{T}$ cage, as well as of their sizes, on the structural and electronic properties of silsesquioxane.

\section{Results and Discussion}

3.1. Structural Properties. Tables 1 and 2 collect total energies and structural parameters which describe bond lengths and bond angles for various $\mathrm{T}$ cages at their optimized geometry on the LDA and NLDA levels of theory. Due to the presence of rings with different sizes in the same T cage, we classify the structural parameters on the basis of the rings which form an edge and do not give their average values over all rings. We use the notation of $N \mathrm{R} / N^{\prime} \mathrm{R}$ to represent the edge formed by an $N$-member and an $N^{\prime}$-member ring. In Table 2, for example, the structural parameters of $3 \mathrm{R} / 4 \mathrm{R}$ represent the values associated with atoms shared by three- and four-member rings.

In the connectivity scheme used here, the $\mathrm{T}_{4}, \mathrm{~T}_{6}$, and $\mathrm{T}_{10}$ cages may only be represented by a single configuration whereas the $\mathrm{T}_{8}, \mathrm{~T}_{12}, \mathrm{~T}_{14}$, and $\mathrm{T}_{16}$ cages may have a few isomeric configurations consisting of four-, five-, and six-member rings. According to Table 1, at the NLDA level, the lowest energy configurations for $T_{12}$ and $T_{14}$ correspond to the $5^{b} 4^{c}$ unit whereas the $T_{16}$ cage prefers the $6^{a} 4^{c}$ unit. The NLDA results therefore reproduce successfully experimental observations ${ }^{2-4}$ about the synthesis of pure $\mathrm{T}_{12}\left(D_{2 d}\right)-5^{4} 4^{4}$ and $\mathrm{T}_{14}\left(D_{3 h}\right)-5^{6} 4^{3}$ compounds. Furthermore, for the $\mathrm{T}_{14}$ cage, a second isomer with the $C_{2 v}$ symmetry is also possible since calculations find a small energy difference between the $D_{3 h}$ and $C_{2 v}$ configura- tions. In fact, X-ray diffraction experiments ${ }^{4}$ have identified the structure of the second isomer to be $C_{2 v}$. In the case of the $\mathrm{T}_{16}$ cage, the major isomer is suggested to be $D_{4 d^{-}}-6^{0} 5^{8} 4^{2}$ on the basis of the observed ${ }^{3}$ linear correlation between the number of four-member rings and ${ }^{29} \mathrm{Si}$ NMR chemical shifts. However, the NLDA results suggest $D_{2 d^{-}} 6^{4} 5^{0} 4^{6}$ to be the major isomer. Although the LDA calculations find $C_{3 v}-6^{1} 5^{6} 4^{3}$ to be the most stable isomer, both synthesis experiments and NLDA calculations do not find this to be the case for $T_{16}$. We conclude therefore that the NLDA level of theory we used is more appropriate for determining major isomers of higher silsesquioxane cages.

Analysis of total energies of various isomers of the $\mathrm{T}$ cages also reveals a progression of the preferred building unit with the increase in cage size. The preference for the four-member rings can be seen for $T_{8}$ while $T_{12}$ prefers $5^{4} 4^{4}$ over $6^{2} 4^{6}$. For $\mathrm{T}_{14}$, a combination of either five- and four-member rings or six-, five-, and four-member rings is preferred. On the other hand, the preference for $6^{4} 4^{6}$ over $5^{8} 4^{2}$ or $6^{1} 5^{6} 4^{3}$ is clearly shown in Table 1 for the $\mathrm{T}_{16}$ cage.

Comparison of LDA and NLDA structural parameters given in Table 2 shows a small increase in $R_{\mathrm{Si}-\mathrm{O}}$ and $A_{\mathrm{OSiO}}$ in NLDA while $A_{\text {SiOSi }}$ generally appears to become smaller in NLDA. For all of the $\mathrm{T}$ cages considered, the increase in the cage size has no effect on the bond lengths $R_{\mathrm{Si}-\mathrm{H}}$ and $R_{\mathrm{Si}-\mathrm{O}}$ but does have a noticeable effect on the bond angle $A_{\mathrm{SiOSi}}$. This is expected due to a large variability of the bond angle which opens to accommodate more atoms as one goes from $T_{4}$ to $T_{16}$. This variability is clearly demonstrated by the results which show a comparatively large range of $140-159^{\circ}$ for $A_{\mathrm{SiOSi}}$ as compared to the range of $110-112^{\circ}$ for $A_{\mathrm{OSiO}}$, respectively (Table $1-\mathrm{cf}$. $\left.\mathrm{T}_{14}\left(C_{2 v}\right)\right)$.

A direct comparison of the calculated bond lengths and bond angles with X-ray diffraction data is not possible since calculations were performed for isolated molecules while the experimental data were obtained with single crystals. The molecular packing of silsesquioxanes in the crystal is expected to modify mainly $A_{\text {SiOSi }}$ due to spatial constraints imposed by the crystalline state, leaving both $R_{\mathrm{Si}-\mathrm{O}}$ and $A_{\mathrm{OSiO}}$ the same as in isolated molecules. For example, the calculated (NLDA) angular spread in $A_{\mathrm{SiOSi}}$ is $137-148^{\circ}$ as compared to the range of $143-164^{\circ}$ for the measured angle ${ }^{14}$ of $\mathrm{T}_{12}\left(D_{2 d}\right)$. On the other hand, both $R_{\mathrm{Si}-\mathrm{O}}$ and $A_{\mathrm{OSiO}}$ are similar in molecular and crystal form with respective values of $168 \mathrm{pm}, 109-111^{\circ}$ and $162 \mathrm{pm}, 108-$ $111^{\circ}$. Both X-ray diffraction data on crystals, and the calculated results for molecules therefore suggest that silsesquioxanes can be described in terms of a network of rigid $\mathrm{HSiO}_{3}$ cages where flexible $\mathrm{Si}-\mathrm{O}-\mathrm{Si}$ angles provide the molecular connectivity.

Looking at the ring-size dependence of the structural parameters, we find a large variation in $R_{\mathrm{Si}-\mathrm{O}}, A_{\mathrm{SiOSi}}$, and $A_{\mathrm{OSiO}}$ in going from a three-member ring $\left(\mathrm{T}_{4}\right)$ to a four-member ring $\left(\mathrm{T}_{8}\right)$ which is in agreement with earlier theoretical ${ }^{23}$ and experimental ${ }^{25}$ studies. Thereafter, both $R_{\mathrm{Si}-\mathrm{O}}$ and $A_{\mathrm{OSiO}}$ show a very small variation in going from a four-member ring to a six-member ring as compared to the variation in $A_{\mathrm{SiOSi}}$.

Comparison of results obtained in the present study using density functional theory with previous calculations based on the Hartree-Fock (HF) approximation ${ }^{23}$ shows well-known differences in the structural parameters arising from the use of two different methodologies. For the $\mathrm{T}_{4}$ cage, $R_{\mathrm{Si}-\mathrm{O}}$ and $R_{\mathrm{Si}-\mathrm{H}}$ are reported to be 165.5 and $145.4 \mathrm{pm}$, respectively, in the HF study as compared to our NLDA values of 171 and $147 \mathrm{pm}$. The HF calculation for the $\mathrm{T}_{12}\left(D_{6 h}\right)$ cage gives these bond lengths as 163 and $146 \mathrm{pm}$ in contrast to our NLDA values of 
TABLE 3: Binding Energies and Energies of the Hydrolysis Reaction for Various Configurations of Silsesquioxanes

\begin{tabular}{|c|c|c|c|c|c|c|c|}
\hline & \multirow{2}{*}{$\begin{array}{l}\text { building } \\
\text { unit }\end{array}$} & \multirow[b]{2}{*}{ sym } & \multicolumn{2}{|c|}{$\begin{array}{l}\text { binding energy/ } \\
\text { Si atom (hartree) }\end{array}$} & \multicolumn{3}{|c|}{$\begin{array}{c}\text { energy of the } \\
\text { hydrolysis reaction/ } \\
\text { Si atom (kcal/mol) }\end{array}$} \\
\hline & & & LDA & $\overline{\text { NLDA }}$ & $\overline{\mathrm{LDA}}$ & NLDA & $\mathrm{HF}^{23}$ \\
\hline $\mathrm{T}_{4}$ & $5^{0} 4^{0} 3^{4}$ & $T_{d}$ & -0.713 & -0.6021 & -5.0 & -5.7 & \\
\hline $\mathrm{T}_{6}$ & $5^{0} 4^{3} 3^{2}$ & $D_{3 h}$ & 0.7234 & -0.6117 & +1.0 & +0.3 & +3 \\
\hline \multirow[t]{2}{*}{$\mathrm{T}_{8}$} & $6^{0} 5^{0} 4^{6}$ & $O_{h}$ & -0.7251 & -0.6137 & +2.1 & +1.6 & +5 \\
\hline & $5^{2} 4^{2} 3^{2}$ & $C_{2 v}$ & -0.7246 & -0.6127 & +1.7 & +1.0 & +4 \\
\hline $\mathrm{T}_{10}$ & $6^{0} 5^{2} 4^{5}$ & $D_{5 h}$ & -0.7249 & -0.6134 & +1.9 & +1.4 & +6 \\
\hline \multirow[t]{2}{*}{$\mathrm{T}_{12}$} & $6^{2} 5^{0} 4^{6}$ & $D_{6 h}$ & -0.7247 & -0.6131 & +1.8 & +1.2 & \\
\hline & $6^{0} 5^{4} 4^{4}$ & $D_{2 d}$ & -0.7255 & -0.6133 & +2.3 & +1.4 & \\
\hline \multirow[t]{3}{*}{$\mathrm{T}_{14}$} & $6^{0} 5^{6} 4^{3}$ & $D_{3 h}$ & -0.7253 & -0.6137 & +2.2 & +1.6 & \\
\hline & $6^{1} 5^{4} 4^{4}$ & $C_{2 v}$ & -0.7257 & -0.6136 & +2.5 & +1.5 & \\
\hline & $6^{3} 5$ & $D_{3 h}$ & -0.6935 & -0.5727 & -17.8 & -24.1 & \\
\hline \multirow[t]{3}{*}{$\mathrm{T}_{16}$} & $6^{0} 5^{8} 4^{2}$ & $D_{4 d}$ & -0.7238 & -0.6127 & +1.2 & +1.0 & \\
\hline & $6^{1} 5^{6} 4^{3}$ & $C_{3 v}$ & -0.7252 & -0.6118 & +2.1 & +0.4 & \\
\hline & $6^{4} 5^{0} 4^{6}$ & $D_{2 d}$ & -0.7250 & -0.6140 & +2.0 & +1.8 & \\
\hline
\end{tabular}

167 and $147 \mathrm{pm}$. A similar variation can be found for the bond angles. The $\mathrm{HF}$ study reports $A_{\mathrm{OSiO}}$ as $105^{\circ}$ in $\mathrm{T}_{4}$ and $110^{\circ}$ in $\mathrm{T}_{12}\left(D_{6 h}\right)$ while the NLDA calculation gives $107^{\circ}$ for $\mathrm{T}_{4}$ and $113^{\circ}$ for $\mathrm{T}_{12}\left(D_{6 h}\right)$. In the $\mathrm{T}_{4}$ and $\mathrm{T}_{12}\left(D_{6 h}\right)$ cages, the respective values of $A_{\mathrm{SiOSi}}$ are 118 and $150^{\circ}$ with $\mathrm{HF}$ and 114 and $163^{\circ}$ using NLDA. Overall, the HF and NLDA values for $R_{\mathrm{Si}-\mathrm{O}}$ and $A_{\mathrm{OSiO}}$ are within $3 \%$ of each other while they are within $10 \%$ of each other for $A_{\mathrm{SiOSi}}$.

Table 1 also gives the energies obtained for the various cages and isomers relative to the value determined for $\mathrm{T}_{4}$, so that the comparison of the LDA and NLDA with the HF energies can be more easily made. In Table 1 , the values are in terms of the total energy per Si atom in units of $\mathrm{kcal} / \mathrm{mol}$. Note that the HF calculations place various $\mathrm{T}$ cages lower in energy than either LDA or NLDA calculations while the calculated stability of isomeric configurations is predicted to be the same by these methodologies. For $\mathrm{T}_{8}$ and $\mathrm{T}_{12}$, the most stable configurations have $O_{h}$ and $D_{2 d}$ symmetries, respectively, in agreement with experiments.

3.2. Stability. Silsesquioxanes are unstable in the presence of hydroxyl groups and can undergo hydrolysis by the following reaction: ${ }^{23}$

$$
\left(\mathrm{HSiO}_{3 / 2}\right)_{n}+(3 / 2) n \mathrm{H}_{2} \mathrm{O}=n \mathrm{HSi}(\mathrm{OH})_{3}
$$

The energetics of this reaction are expected to depend on the binding energy for a particular cage configuration and on the
TABLE 4: Fragmentation Energetics of Silsesquioxanes Calculated Using Total Energies of the Optimized Configurations

\begin{tabular}{|c|c|c|}
\hline \multirow[b]{2}{*}{ fragmentation path } & \multicolumn{2}{|c|}{$\begin{array}{c}\text { fragmentation energy } \\
(\mathrm{kcal} / \mathrm{mol})\end{array}$} \\
\hline & LDA & NLDA \\
\hline $\mathrm{T}_{8} \rightarrow \mathrm{T}_{4}+\mathrm{T}_{4}$ & 56.4 & 58.0 \\
\hline $\mathrm{T}_{10} \rightarrow \mathrm{T}_{6}+\mathrm{T}_{4}$ & 32.9 & 35.1 \\
\hline $\mathrm{T}_{12} \rightarrow \mathrm{T}_{4}+\mathrm{T}_{4}+\mathrm{T}_{4}$ & 87.7 & 84.4 \\
\hline$\rightarrow \mathrm{T}_{8}+\mathrm{T}_{4}$ & 31.3 & 26.4 \\
\hline$\rightarrow \mathrm{T}_{6}+\mathrm{T}_{6}$ & 15.9 & 12.5 \\
\hline $\mathrm{T}_{14} \rightarrow \mathrm{T}_{6}+\mathrm{T}_{4}+\mathrm{T}_{4}$ & 68.2 & 66.0 \\
\hline$\rightarrow \mathrm{T}_{10}+\mathrm{T}_{4}$ & 35.3 & 30.9 \\
\hline$\rightarrow \mathrm{T}_{8}+\mathrm{T}_{6}$ & 11.8 & 8.0 \\
\hline $\mathrm{T}_{16} \rightarrow \mathrm{T}_{8}+\mathrm{T}_{4}+\mathrm{T}_{4}$ & 57.5 & 61.6 \\
\hline$\rightarrow \mathrm{T}_{6}+\mathrm{T}_{6}+\mathrm{T}_{4}$ & 42.0 & 47.7 \\
\hline$\rightarrow \mathrm{T}_{12}+\mathrm{T}_{4}$ & 26.2 & 35.2 \\
\hline$\rightarrow \mathrm{T}_{10}+\mathrm{T}_{6}$ & 9.1 & 12.6 \\
\hline$\rightarrow \mathrm{T}_{8}+\mathrm{T}_{8}$ & 1.1 & 3.6 \\
\hline
\end{tabular}

TABLE 5: Compositions of HOMO and LUMO States in the (NLDA) Optimized Configurations of Silsesquioxanes in Terms of Percentage of Total Population

\begin{tabular}{|c|c|c|c|c|c|c|c|c|}
\hline & \multirow[b]{2}{*}{ state } & \multicolumn{3}{|c|}{ HOMO } & \multirow[b]{2}{*}{ state } & \multicolumn{3}{|c|}{ LUMO } \\
\hline & & $\mathrm{Si}$ & $\mathrm{O}$ & $\overline{\mathrm{H}}$ & & $\mathrm{Si}$ & $\mathrm{O}$ & $\mathrm{H}$ \\
\hline $\mathrm{T}_{4}(1$ & $\mathrm{T}_{1}$ & 0.3 & 1.7 & 0 & $\mathrm{E}$ & 0.94 & 0.43 & 0.63 \\
\hline $\mathrm{T}_{6}\left(D_{3 h}\right)$ & $\mathrm{E}^{\prime}$ & 0.15 & 1.85 & 0 & $\mathrm{~A}_{1}^{\prime}$ & 0.24 & 0.61 & 0.15 \\
\hline $\mathrm{T}_{8}\left(O_{h}\right)$ & $\mathrm{A}_{2 \mathrm{~g}}$ & 0 & 1.0 & 0 & $\mathrm{~A}_{1 \mathrm{~g}}$ & 0.3 & 0.54 & 0.16 \\
\hline $\mathrm{T}_{10}\left(D_{5 h}\right)$ & $\mathrm{E}_{2}^{\prime}$ & 0.1 & 1.9 & 0 & $\mathrm{~A}_{1}^{\prime}$ & 0.25 & 0.41 & 0.34 \\
\hline $\mathrm{T}_{12}\left(D_{2 d}\right)$ & E & 0.1 & 1.9 & 0 & $\mathrm{~A}_{1}$ & 0.21 & 0.37 & 0.42 \\
\hline $\mathrm{T}_{14}\left(D_{3 h}\right)$ & $\mathrm{A}_{1}^{\prime \prime}$ & 0.03 & 0.97 & 0 & $\mathrm{~A}_{2}^{\prime \prime}$ & 0.16 & 0.02 & 0.82 \\
\hline $\mathrm{T}_{16}\left(D_{2 d}\right)$ & $\mathrm{B}_{2}$ & 0.03 & 0.97 & 0 & $\mathrm{E}$ & 0.33 & 0.02 & 1.65 \\
\hline
\end{tabular}

different fragmentation paths taken. Table 3 shows these energies per $\mathrm{Si}$ atom for the cages for which Table 1 lists the total energies. It is seen that this hydrolysis reaction is an endothermic process except for the $\mathrm{T}_{4}$ cage. This is consistent with experimental observations and previously published theoretical calculations. The NLDA calculations find the energy of the hydrolysis reaction per $\mathrm{Si}$ atom in the range $0.3-1.8 \mathrm{kcal} /$ mol, indicating that the isomeric configurations considered are relatively stable. We note here that the HF calculations ${ }^{23}$ yield considerably higher values (in the range $3.4-6.4 \mathrm{kcal} / \mathrm{mol}$ ) for this reaction energy.

The binding energy with respect to atomic constituents increases from $\mathrm{T}_{4}$ to $\mathrm{T}_{8}$, as expected, and then remains essentially constant, independent of the cage size, for both LDA and NLDA levels of theory, having values of 0.72 and 0.61

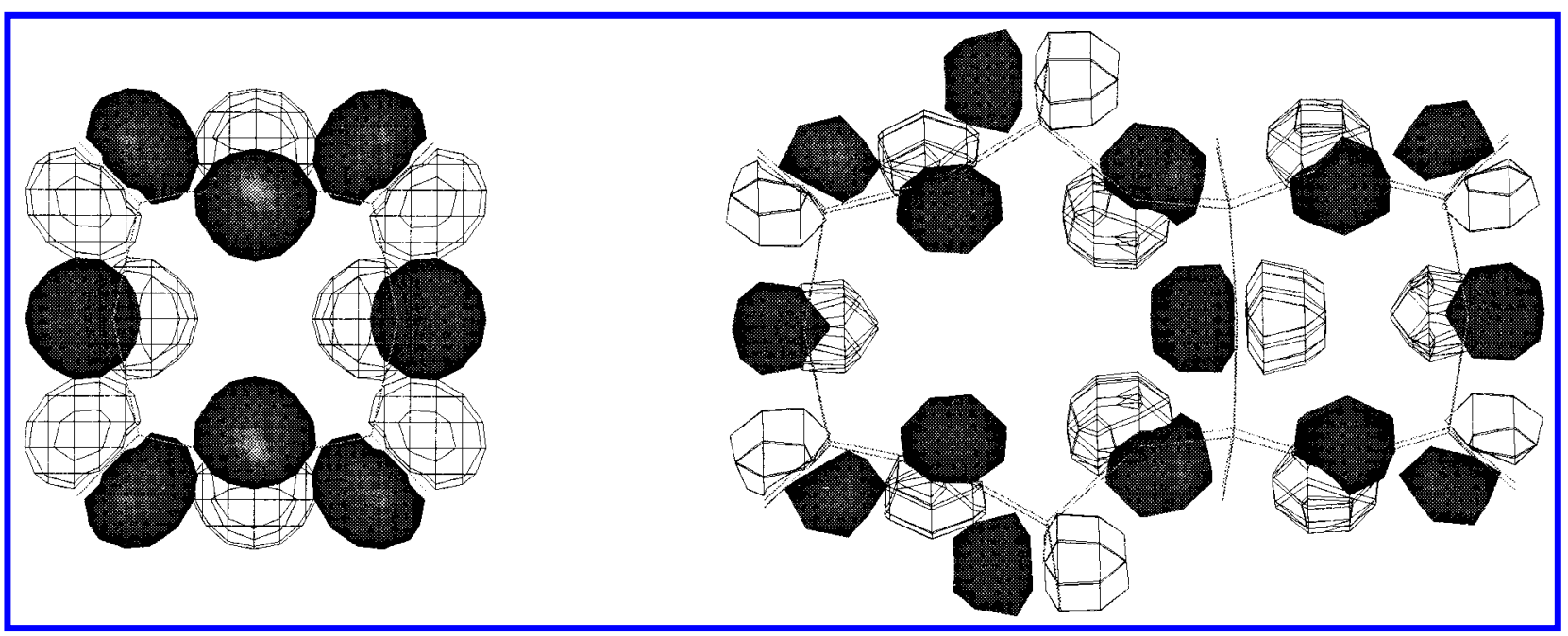

Figure 3. HOMO contours: (left) $\mathrm{T}_{8}\left(O_{h}\right)$; (right) $\mathrm{T}_{16}\left(D_{2 d}\right)$. Negative (dark solid contours) and positive (lines) regions are plotted with contours of $0.02 \mathrm{e} / \mathrm{bohr}^{3}$. 

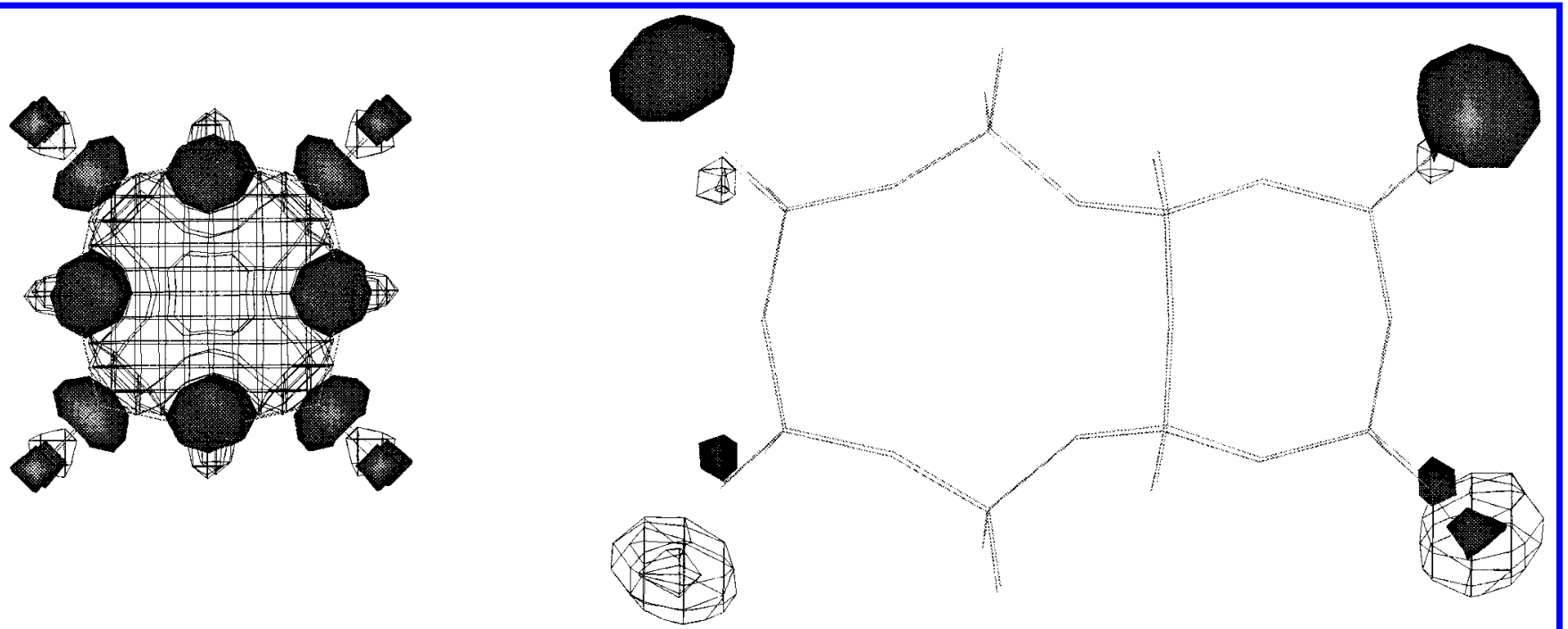

Figure 4. LUMO contours: (left) $\mathrm{T}_{8}\left(O_{h}\right)$; (right) $\mathrm{T}_{16}\left(D_{2 d}\right)$. Negative (dark solid contours) and positive (lines) regions are plotted with contours of $0.028 \mathrm{e} / \mathrm{bohr}^{3}$.
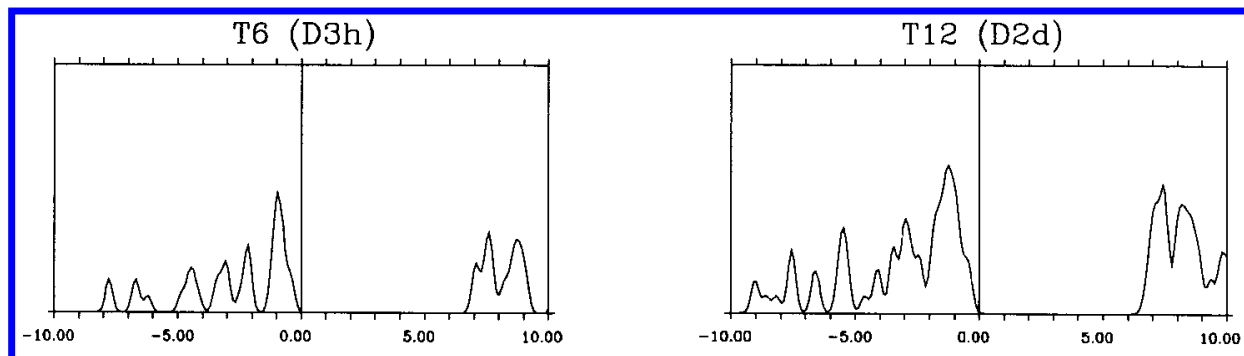

$\mathrm{T} 8(\mathrm{Oh})$

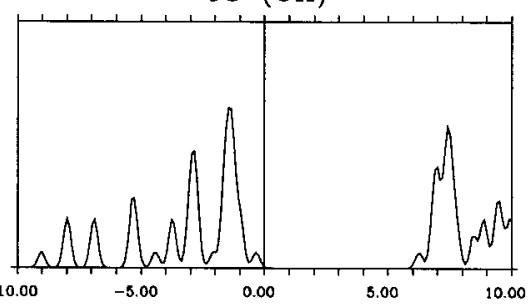

T10 (D5h)

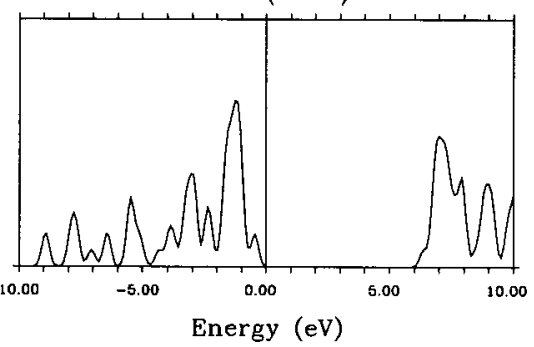

T14 (D3h)

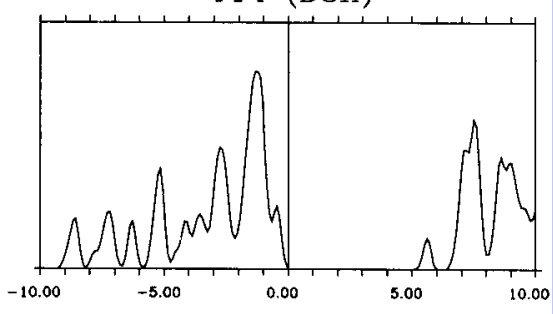

T16 (D2d)

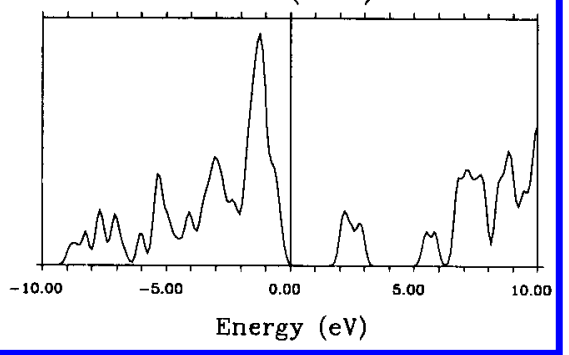

Figure 5. Total density of states plots for the optimized configurations of the $\mathrm{T}$ cages considered.

hartree per Si atom, respectively. Due to small differences in binding energies, the calculated results predict that various isomers of a given $\mathrm{T}$ cage can coexist, as is also observed in synthesis experiments. ${ }^{2,3}$

Calculations of the fragmentation energies with regard to all possible pathways support the above results in terms of the relative stability of the $T$ cages considered in this study. Table 4 gives the fragmentation energies computed using the total energy of the most stable configurations. The dissociation of the $\mathrm{T}_{16}$ cage into two $\mathrm{T}_{8}$ cages appears to have the lowest fragmentation energy followed by the dissociation of the $T_{14}$ cage. On the other hand, $\mathrm{T}_{8}, \mathrm{~T}_{10}$, and $\mathrm{T}_{12}$ cages appear to be the most stable against fragmentation into smaller $\mathrm{T}$ cages.

3.3. Electronic Properties. In this section, we present the results of the analysis of electronic properties of $\mathrm{T}$ cages in terms of density of states (DOS), deformation charge densities, highest occupied molecular orbitals (HOMOs), lowest unoccupied molecular orbitals (LUMOs), and Mulliken populations.

The spatial extents of the HOMOs and LUMOs for $\mathrm{T}_{8}\left(O_{h}\right)$ and $\mathrm{T}_{16}\left(D_{2 d}\right)$ are shown in Figures 3 and 4. The (lone-pair) oxygen p-type atomic orbitals form HOMOs in both $\mathrm{T}_{8}$ and $\mathrm{T}_{16}$ (Figure 3) while a combination of atomic orbitals associated 


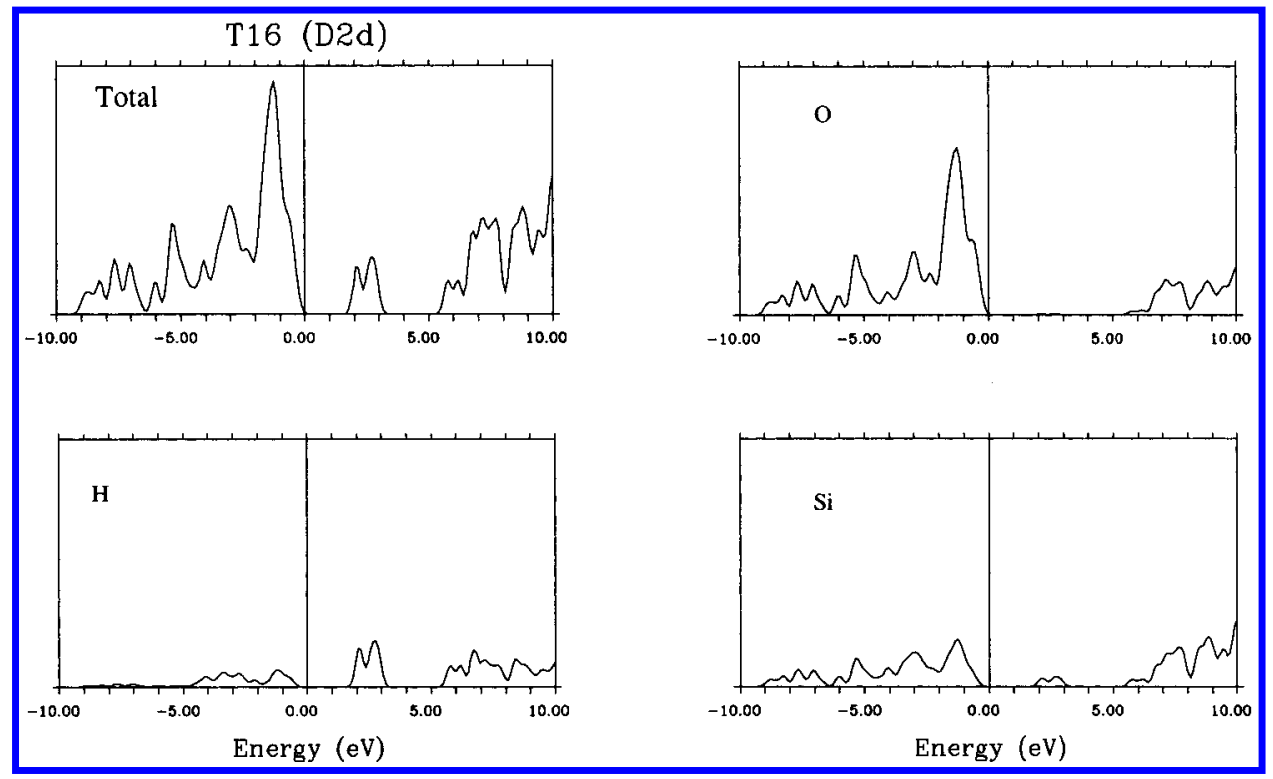

Figure 6. Projected density of states plots for $\mathrm{T}_{16}$.

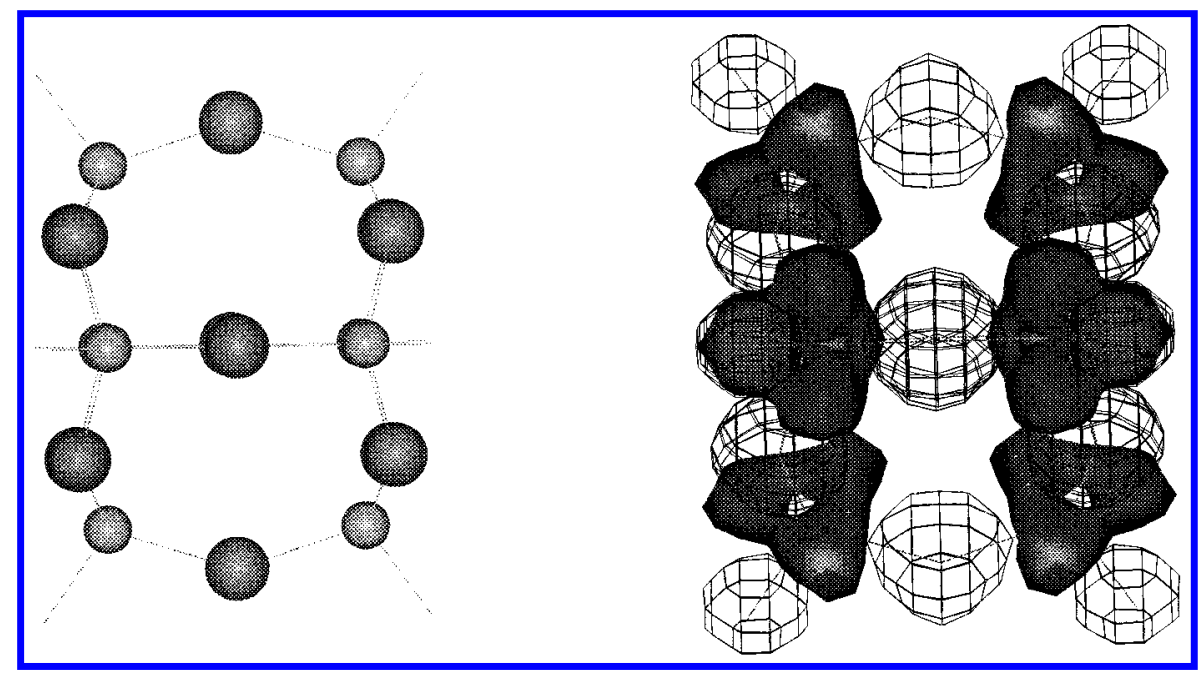

Figure 7. Deformation electronic density maps for $\mathrm{T}_{8}\left(O_{h}\right)$. Negative (lines) and positive (dark solid contours) regions represent zones of surplus and lack of electronic density respectively and are plotted with contours of $0.01 \mathrm{e} / \mathrm{bohr}^{3}$. In the accompanied ball-and-stick representation of $\mathrm{T}_{8}$, the smaller circles represent silicons and the larger circles represent oxygens. The hydrogen atoms, not shown in the figure, are attached to silicons.

with $\mathrm{Si}, \mathrm{O}$, and $\mathrm{H}$ forms the LUMO for $\mathrm{T}_{8}$. Interestingly, the percentage of the oxygen orbital mixing with the silicon and hydrogen orbitals for the LUMO decreases with the increase in the cage size, and in the case of $\mathrm{T}_{16}$, the LUMO is marked by a negligible presence of oxygen orbitals (Figure 4). This is confirmed by Table 5, which shows the composition of the HOMO and LUMO orbitals for the most stable configurations of various $\mathrm{T}$ cages.

Density of states (DOS) for silsesquioxanes was analyzed using a Gaussian broadening scheme with a value of $0.15 \mathrm{eV}$, which was used to widen the discrete peaks of the $\mathrm{T}$ cages. Figure 5 compares the DOS plots for the $\mathrm{T}$ cages considered here where we have assigned the top of the occupied state to zero. As expected from the nature of the HOMOs, the highest occupied state is formed solely by the oxygen $\mathrm{p}$ lone-pair nonbonding orbitals. The $\mathrm{O}$ s orbitals are well separated from the $\mathrm{O}$ p orbitals and occur about $17 \mathrm{eV}$ below the top of the occupied states. Adjacent to the highest occupied state, the DOS plots show a clustering of states up to about $9 \mathrm{eV}$ wide below the top which is mainly due to bonding orbitals of silicon s-type and oxygen p-type orbitals.
The HOMO-LUMO gap shows a small variation with the cage size decreasing from $7.4 \mathrm{eV}$ in $\mathrm{T}_{6}$ to $6.2 \mathrm{eV}$ in $\mathrm{T}_{16}$. In the absence of experimental values of the gap for $\mathrm{T}$ cages, we can only make comparison of the calculated gap values with the known value $\mathrm{e}^{26}$ of about $9 \mathrm{eV}$ for $\alpha$-quartz. Note that calculations based on density function theory are known to underestimate the actual energy gap. A previous electronic structure calculation based on the extended-Hückel approximation ${ }^{27}$ has reported the HOMO-LUMO gap to be of the order of 12-14 $\mathrm{eV}$ for the $\mathrm{T}_{8}$ cage, which is too large a value for silica.

The DOS plots for the series of different silsesquioxane cages given in Figures 5 and 6 reveal that for the largest one analyzed, the $\mathrm{T}_{16}$ cage, the LUMO introduces a state in the HOMOLUMO gap. The projection of the total DOS to constituent atoms of the $\mathrm{T}_{16}$ cage finds this midgap state to be associated with the terminal hydrogens attached to silicons in the cage. The appearance of this state is remarkable in that it offers an explanation for the electrical bistability observed in the $j V$ characteristics of metal-insulator-metal devices prepared from the HSQ resin thin films with changes in conduction over 3 orders of magnitude. ${ }^{9}$ This finding also suggests that larger 
size cages in H-silsesquioxane could affect the dielectric properties of such materials.

The contour plots of the deformation charge density illustrate the electronic distribution in the bond formation for $\mathrm{T}_{8}$ in Figure 7. Here, regions of excess electron density are shown with line contours and regions deficient of electron density are mapped by dark solid contours. Accordingly, deviations in sphericity of the electronic clouds display the presence of polarization effects that arise due to the charge transfer from $\mathrm{Si}$ to $\mathrm{O}$. Mulliken population analysis at the NLDA level of theory associates charges of $+1.0 \mathrm{e}$ and $-0.7 \mathrm{e}$ with $\mathrm{Si}$ and $\mathrm{O}$ atoms in these clusters, respectively, and does not show any dependence on the cluster size. This is to be expected since the nature of chemical bonding in silsesquioxanes is mainly determined by the building block, $\left(\mathrm{HSiO}_{3 / 2}\right)$, and is not influenced by an increase in its size.

\section{Summary}

In this work, H-silsesquioxane cages of various sizes and conformations are studied in the framework of density functional theory. We use the LDA and NLDA levels of theory and the numerical basis set for electronic structure calculations. Although the results are consistent in LDA and NLDA, the reliable prediction of the most stable isomer for larger $\mathrm{T}$ cages requires the use of the NLDA level of theory. The calculated total energies show a clear preference for four- and five-member rings by the smaller cages and for four- and six-member rings by the larger cages. A detailed analysis of binding energy, energy for the hydrolysis reaction, and fragmentation paths suggests the relative stability of $\mathrm{T}_{8}, \mathrm{~T}_{10}$, and $\mathrm{T}_{12}$ cages. Both $\mathrm{T}_{4}$ and $\mathrm{T}_{6}$ cages which contain three-member rings are found to be relatively unstable against hydrolysis in accordance with the results of experiments and earlier Hartree-Fock calculations. The (lonepair) oxygen p-type atomic orbitals form the HOMO of the T cages considered while the terminal hydrogens associated with silicons appear to give rise to an electronic state in the HOMOLUMO gap for the larger T cages.

Acknowledgment. This project was financially supported by the Dow Corning Corp. K.-H.X. acknowledges the Michigan Technological University for a Graduate Research Fellowship.

\section{References and Notes}

(1) Calzaferri, G. Tailor-made silicon oxygen compounds: from molecules to materials; Corriu, R., Jutzi, P., Eds.; Braunschweig: Wiesbaden, Germany, 1996.

(2) Frye, C. L.; Collins, W. T. J. Am. Chem. Soc. 1990, 92, 5586. 335.

(3) Agaskar, P. A.; Klemperer, W. G. Inorg. Chim. Acta 1995, 229,

(4) Agaskar, P. A.; Day, V. W.; Klemperer, W. G. J. Am. Chem. Soc. 1987, 109, 5554 .

(5) Marcolli, C.; Laine, P.; Buhler, R.; Calzaferri, G.; Tompkinson, J. J. Phys. Chem. B 1997, 101, 1171 .

(6) Bornhauser, P.; Calzaferri, G. J. Phvs. Chem. 1996, 100, 2035.

(7) Bartsch, M.; Bornhauser, P.; Calzaferri, G.; Imhof, R. J. Phvs. Chem. 1994, 98, 2817.

(8) Chandra, G. Mater. Res. Soc. Symp. Proc. 1991, 203, 97.

(9) Pernisz, U. C. Proc. Electroceramics 1994, 4, 823.

(10) Larson, K. Ark. Kemi 1960, 16, 215.

(11) Burgy, H.; Calzaferri, G. J. Chromatogr. 1990, 507, 481.

(12) auf der Heyde, T. P. E.; Burgi, H.-B.; Burgy, H.; Tornroos, K. W. Chimia 1991, 45, 38.

(13) Tornroos, K. W. Acta Crvstallogr. 1994, C50, 1646.

(14) Tornroos, K. W.; Burgi, H.-B.; Calzaferri, G.; Burgy, H. Acta Crystallogr. 1995, B51, 155.

(15) DMol User Guide, version 2.3.6; Molecular Simulations Inc.: San Diego, CA, 1996.

(16) Vosko, S. H.; Wilk, L.; Nusair, M. Can. J. Phys. 1980, 58, 1200.

(17) Becke, A. D. Phvs. Rev. A 1988, 38, 3098.

(18) Rosen, A.; Ellis, D. E.; Adachi, H.; Averill, F. W. $\underline{\text { J. Chem. Phys }}$ 1976, 65, 3629.

(19) Delley, B. J. Chem. Phvs. 1990, 92, 508.

(20) Veliah, S.; Pandey, R.; Newsam, J.; Vessal, B. Chem. Phvs. Lett. 1995, 235, 53.

(21) Veliah, S.; Xiang, K.; Pandey, R.; Recio, J. M.; Newsam, J. J. Phys. Chem. 1998, 102, 1126.

(22) Pasquarello, A.; Hybertsen, M. S.; Car, R. Phvs. Rev. B 1996, 54, R2339.

(23) Earley, C. J. Phys. Chem Soc. 1994, 98, 8693.

(24) Hill, J.-R.; Sauer, J. J. Phvs. Chem. 1994, 98, 1238.

(25) Oberhammer, H.; Zeil, W.; Fogarasi, G. J. Mol. Struct. 1973, 18, 309.

(26) DiStefano, T. H.; Eastman, D. E. Solid State Commun. 1971, 9, 2259.

(27) Calzaferri, G.; Hoffman, R. J. Chem. Soc. Dalton Trans. 1991, 